\title{
Entre IsRael E A PAlestina PODERIA haVer UM MANDEla
}

Magno Paganelli ${ }^{1}$

\section{Between IsRael and Palestine could Be A Mandela}

\begin{abstract}
RESUMO. 0 presente ensaio pretende indicar a necessidade do diálogo e de abordagens conciliatórias em contextos diversos, tomando como modelo o processo de pacificação étnica ocorrido na África do Sul. A opção do presente autor contempla a situação de Apartheid no conflito Israel-Palestina como objeto e destaca apenas um dos seus inúmeros aspectos, a ocupação, propondo como paradigma no caminho para a paz a atuação de Nelson Rolihlahla Mandela, Prêmio Nobel da Paz em 1993, em sua luta contra a segregação racial naquele país. ${ }^{2}$
\end{abstract}

PALAVRAS-CHAVE: Mandela; Israel; Palestina; Apartheid; pacificação.

\begin{abstract}
This essay intends to indicate the need for dialogue and conciliatory approaches in diverse contexts, taking as a model the process of ethnic pacification that took place in South Africa. The present author's option contemplates the situation of Apartheid in the Israel-Palestine conflict as an object and highlights Only one of its many aspects, the occupation, proposing as a paradigm on the road to peace the performance of Nelson Rolihlahla Mandela, 1993 Nobel Peace Prize winner, in his fight against racial segregation in that country.
\end{abstract}

KEY-WORDS: Mandela; Israel; Palestine; Apartheid; pacification.

\section{INTRODUÇÃo}

O Século XX viu surgir e desaparecer conflitos motivados por razões as mais diversas. Esses confrontos, civis ou militares, carregaram interesses econômicos, geoestratégicos, colonialistas, territoriais, políticos, entre outros e é animador saber que muitos deles encontraram solução adequada e justa, chegando ao seu final; outros ainda estão sendo concluídos em nossos dias, como na América do Sul, onde as Forças Revolucionárias da Colômbia, as FARCs, negociam a parte final do processo de pacificação com o Governo e a população, adequando a integração da guerrilha ao sistema político no pais vizinho³.

Do saldo dos conflitos no século passado, um ainda persiste entre avanços e retrocessos na procura por solução justa, sustentável e duradoura. Entre israelenses e

\footnotetext{
${ }^{1}$ Magno Paganelli é doutorando em História Social (USP), Mestre em Ciências da Religião (Mackenzie), Bacharel em Teologia com especialização em Novo Testamento. É Jornalista, Pedagogo com pós-graduação em Didática do Ensino Superior (Mackenzie) e membro do GTOMMM (USP/CNPq). http://buscatextual.cnpq.br/buscatextual/visualizacv.do?id=K4047200P6 Contato: paganelli.magno@gmail.com

20 artigo que deu origem a este ensaio ficou em 1ํㅡ lugar no Concurso de Artigos do Centro Cultural Brasil-Turquia (CCBT), na categoria Pós-graduação. 0 evento ocorreu no âmbito do Seminário Heróis da Paz no dia 27.10.2016, na Fundação Escola de Sociologia Política de São Paulo. 0 edital do concurso convocou acadêmicos a reflexão sobre e a promoção da paz, em abordagem que estimule nos jovens o conhecimento histórico que oriente o caminho da paz.

3 A imprensa tem reportado constantemente o passo a passo do processo na Colômbia. Disponível em http://brasil.elpais.com/brasil/2016/09/26/internacional/1474912709_711206.html e acessado em $1^{\circ} .10 .2016$.
} 
palestinos encontramos o conflito com maior duração de todos; e devemos notar não haver no horizonte sinalização tal qual vemos na Colômbia. Evidentemente, a natureza das discórdias é distinta e diversificada, bem sabemos. Mas em determinados pontos se equiparam. Em um ensaio como este, o pouco espaço nos trai, impedindo desenvolver com profundidade cada ponto; em compensação não falta literatura sobre o caso.

Nas décadas que seguiram a fundação do moderno Estado de Israel, em 1948, houveram muitos mediadores entre israelenses e palestinos procurando acomodação adequada, segura e justa para as populações. Governos de diversos países, organismos e instituições internacionais e, por vezes, os próprios representantes legais em reuniões diretas e de alto nível tentaram a solução para o impasse (SHLAIM, 2004, passim). Diante disso, a partir das considerações propostas no RESUMO deste ensaio, apresentarei uma abordagem pouco considerada para a questão, que chamarei de "o paradigma de Mandela", e procurarei chamar a atenção dos leitores sobre o modo como "o paradigma" pode ser modelo para nossas próprias vidas, para a resolução de conflitos que nos cercam e para a construção do nosso mundo no século XXI.

\section{BREVÍSSIMA HISTÓRIA DO CONFLITO}

Num período em que a Europa respirava ares de ameaça contra as variadas comunidades judaicas, surgiu entre os judeus o movimento sionista. ${ }^{4} 0$ objetivo do movimento era estabelecer aquele povo num "lar nacional na Palestina" (cfm. Declaração de Balfour, de 2 de janeiro de 1917, documento oficial do Mandato Britânico; SAID, 2012, p. 18). Os britânicos detinham poderes na região ${ }^{5}$ e ao longo dos anos os judeus formaram outras instituições com a finalidade de promover a mudança da população, ${ }^{6}$ nem sempre guiadas pelos mesmos princípios, mas sempre visando os mesmos objetivos.

As ondas migratórias vindas da Europa levavam anualmente milhares de judeus animados com a possibilidade de estabelecerem na nova terra as suas colônias, o kibutz. O kibutz são

[...] povoamentos agrários maiores sem propriedade privada, com refeições e educação infantil comuns, o coletivo agrário menor, a kevutsa, e o moshav, assentamento cooperativista de pequenos agricultores no qual as famílias têm sua vida e seu trabalho separados (GUNNEWEG, 2005, p. 324; ênfase no original).

\footnotetext{
${ }^{4}$ Um dos grandes nomes do movimento sionista foi Theodor Herzl (1860-1904). Herzl conseguiu apoio dos britânicos por meio do Barão Rothschild, a fim de enviar judeus para "o novo lar", a Palestina. Na ocasião havia cerca de 24 mil judeus na Palestina e as primeiras ondas migratórias vindas da Europa datam de 1880 (GUNNEWEG, 2005, p. 319).

5 Sobre os poderes dos britânicos na região e alhures, veja também Acordo Sykes-Picot, de 1916.

${ }^{6}$ Entre elas, destacam-se Howewei Tsion, Jewish Territorial Organization, Keren Kayemet Leyisrael (Fundo Nacional Judeu), Paolei Tsion (Trabalhadores de Sião, movimento socialista-sionista russo), a Anglo-Palestine Company, Jewish Colonial Trust (Londres), entre outras (GUNNEWEG, 2005, p. 320-321).
} 


\section{ensaio}

O Império Otomano havia feito da Palestina uma província em 1516. A população era majoritariamente muçulmana sunita de fala árabe. Entre as minorias havia cristãos, drusos, muçulmanos xiitas. E havia comunidades de judeus na Palestina (SAID, 2012, p. 14). Os judeus da Europa, no entanto, já vinham sendo perseguidos há tempos. Joseph Pérez (2007, p. 2), historiador e hispanista indica o seguinte quadro de expulsões feitas contra judeus: Espanha (1492), Viena e Linz (1421), Colônia (1424), Augsburg (1439), Baviera (1442), Morávia (1454), Perugia (1485), Vicenza (1486), Parma (1488), Milão e Lucca (1489), Toscana (1494).

Pouco antes das primeiras migrações de judeus vindos da Europa, a partir de 1880, a população de judeus na Palestina chegava a 24.000 pessoas (GUNNEWEG, 2005, p. 319. The Anglo-Palestine Yearbook 1947-8, p. 33, apud SAID, 2012, p. 13). As migrações despejaram um maciço contingente de judeus entre os árabes que lá estavam, o que naturalmente provocou desestabilizações sociais em determinados setores, além de revolta. "Em 1931 a população judaica [já] era de 174.606 pessoas entre um total de 1.033.314; em 1936 o número de judeus subiu para 384.078 entre 1.366.692; e em 1946 eles eram 608.225 numa população total de 1.912.112" (SAID, 2012, p. 13).

A despeito dos inúmeros fatores que permeiam "a questão da palestina" (SAID, 2012, passim), meu enfoque no presente ensaio será a terra e a presença de dois povos em sua ocupação. Em expressão concisa e preliminar, é a ocupação da terra que dispara o conflito, se considerarmos a sua origem no final do século XIX.7 Nossa atenção, então, se voltará para esse aspecto.

\section{A QUESTÃO DA TERRA}

O lema que o movimento sionista propagandeou pela Europa entre os séculos XIX e XX dizia haver na Palestina uma "terra sem povo, para um povo sem terra" (FARAH, 2013). Os judeus poderiam não ter uma terra, mas a terra tinha um povo. 0 professor Farhat $(2013)^{8}$ cita a declaração de Ascher Ginzberg, um judeu russo (conhecido em Israel por Ahad Ha'am), que esteve na Palestina pela primeira vez em 1891 e fez fartas alusões sobre os "campos cultivados por toda a Palestina" e da "falsa ideia de que os árabes eram incultos e selvagens do deserto" (FARHAT, 2013).

Edward Said, acadêmico palestino, tocou o cerne da questão quando afirmou:

\footnotetext{
${ }^{7}$ Hoje estão envolvidos fatores econômicos, como em Gaza, com as reservas de gás na região litorânea, a questão da água, a exploração das reservas de pedra, questões militares que atraem os Estados Unidos e a Rússia, entre outras. Na raiz da questão consideramos Israel como vítimas da perseguição nos países da Europa desde o século 16 (v. p. 3-4), culminando no Holocausto.

${ }^{8}$ Paulo Daniel Elias Farah possui graduação em Língua e Literatura Árabe, graduação em Letras Português, mestrado em Linguística e doutorado em Letras, todos pela USP, onde é professor.
} 
Uma das supostas distinções jurídicas entre povos civilizados e incivilizados era a atitude em relação à terra, quase uma doxologia da terra, que os povos incivilizados supostamente não possuíam. Acreditava-se que um homem civilizado podia cultivar a terra porque esta tinha um significado para ele [...] No caso do povo incivilizado, a terra era mal cultivada [...] ou abandonada (SAID, 2012, p. 85).

A ocupação da Palestina é considerada ilegal dos pontos de vista jurídico e dos direitos humanos; as Resoluções 242 e 338 da ONU já deixaram isso claro na ocasião da sua publicação e instituições de caráter jurídico confirmam o caráter ilegal da questão. ${ }^{9} \mathrm{~A}$ situação tem um peso maior sobre os médio-orientais por causa das suas características geográficas e da organização social local. Diferente do que se costuma pensar, as divisões nacionais comuns ao Ocidente não eram tão comuns naquela região até cerca de cem anos, quando os judeus tentavam implantar na Palestina o modelo político e social europeu.

Ali Kamel, sociólogo, filho de pais e avós sírios e casado com uma judia, pesquisou a questão. Ele conta que França e Grã-Bretanha receberam da Liga das Nações "o Oriente Médio como área a ser 'supervisionada' até que a independência pudesse ser 'concedida' àqueles povos" (KAMEL, 2007, p. 114). A Grã-Bretanha comprometeu-se com os chefes árabes (em seu texto ele usou a expressão "jurou" em vez de comprometeu-se) "torná-los os governadores de suas nações. 0 problema começa aí: que nações? Era preciso inventálas" (KAMEL, 2007, p. 114) em meados do século XX. E foi assim que nasceram, ou melhor, foram criadas a Arábia Saudita, a Palestina e a Jordânia, o Iraque e o Irã, a Indonésia, a Índia (KAMEL, 2007, p. 114; PAGANELLI, 2014b, p. 83). Estou mencionando isso, para realçar que a relação entre os povos locais (relação entre eles mesmos e relação no que diz respeito à ocupação da terra) era diferente de como europeus e americanos viam a si na relação com a terra e como viam o clã ou a aldeia/tribo.

Em um texto escrito sobre os imigrantes sírios e libaneses, dois autores que publicaram obras no Brasil concordam que esses povos geograficamente vizinhos têm em comum uma estrutura social apoiada nos valores étnicos ligados a família, a religião e a aldeia (KNOWLTON, 1961, p. 167; TRUZZI, 2005, p. 3). Um deles, Truzzi, não considera neste tripé, por exemplo, o idioma, ou seja, a língua como fator de identificação de um povo, e justifica:

Embora a região territorialmente pertença ao chamado mundo árabe moderno, e seus habitantes efetivamente serem falantes da língua árabe, os sírios e libaneses identificam-se, sobretudo, com a religião professada e com a região ou aldeia

\footnotetext{
${ }^{9}$ A Suprema corte de Israel e organizações internacionais de Direitos Humanos. Veja, por exemplo, s/a, Israeli court rules against illegal settlement. Associated Press in Jerusalem, 26.mar.2012. Disponível em https://www.theguardian.com/world/2012/mar/26/israeli-court-rules-against-illegal-settlement e acessado em 10.10.2016. ASTON, John. Israel boycott ban: Local councils face legal action at High Court over boycott on Israeli goods made in West Bank. 04.mai2016. Disponível em <http://www.independent.co.uk/ news/uk/home-news/israel-boycott-ban-local-councils-face-legal-action-at-high-court-over-boycott-on -israeli-goods-made-a7012351.html> e acessado em 10.10.2016.
} 
de origem, elementos fundadores de suas identidades, muito mais que com o estado-nação, existente para eles na época da emigração. Em consequência, a identidade árabe lhes soa artificial (TRUZZI, 2005, p. 2).

Dentro deste quadro de referência, a aldeia é o ponto central, onde os valores são passados às gerações e onde se realiza o convívio entre duas, três ou até mesmo quatro gerações simultaneamente e no mesmo espaço. Seria o equivalente ao conceito de família na teoria de George Sorel quando escreve sobre a origem da violência. ${ }^{10}$

Se a família constitui elemento fundamental de reprodução de valores - entre os quais a honra familiar desempenha papel de destaque -, a aldeia representa o locus onde tais valores foram cultivados e onde as gerações anteriores da família viveram. (TRUZZI, 2005, p. 3, ênfase no original)

Sendo a religião, como diz Truzzi, tão pronunciada na identidade do povo da aldeia e se de fato ela e os demais valores identitários são transmitidos entre o grupo, é certo que elementos rituais (de perfil espiritualista) sejam rapidamente elaborados dentro do mercado de produtores de serviços, como Pierre Bourdieu ${ }^{11}$ interpreta. Em outras palavras, não é a língua que criará o universo de referência para determinado povo, antes, tal exercício se dará no interior e no ambiente dos rituais, das liturgias e das rotinas religiosas que delimitarão e traduzirão os significados e os valores para a comunidade.

Fechando mais o ângulo de observação, Farah (2011) apoia a ideia de que a terra e a relação do homem com ela, exerce importante papel na manutenção da vida e na construção da identidade palestina. Em um de seus artigos, ele trata o tema da terra a partir da obra do escritor palestino Ghassan Kanafani, cuja família precisou abandonar a Palestina, rumo ao Líbano após 1948, ano de fundação de Israel.

De fato, a relação do palestino com a terra constitui a problemática essencial da grande maioria dos romances e dos contos de Kanafani, autor que associa árvores que caracterizam essa paisagem (vista como prolongamento natural do lar), como a oliveira, a laranjeira e a videira, ao apego à terra natal, ao futuro e à esperança. (FARAH, 2011) ${ }^{12}$

Said pintou o mesmo quadro ao dizer que "a sociedade palestina foi organizada em linhas feudais e tribais" (SAID, 2012, p. 202). É este cenário poético, de um povo da terra, conectado a ela pelo labor e que por meio dela vive e se manifesta, mas ao mesmo tempo

${ }^{10}$ SOREL, G. Reflexões sobre a violência. São Paulo: Martins Fontes, 1992.

${ }^{11}$ BOURDIEU, Pierre. A economia das trocas simbólicas, 7a ed. São Paulo: Perspectiva, 2011. Bourdieu interpreta a dinâmica dos campos religioso, intelectual, educacional, artístico, cultural e social como trocas, uma relação dialética de afirmação e reafirmação entre produtores de serviços e consumidores. É weberiano neste sentido e segue Durkheim quando vê na sociedade aquilo que a religião vê no sagrado.

${ }^{12}$ A forte identificação com a terra já aparece na primeira frase do livro "Homens ao sol" (de 1963) "AbuQays repousou o peito na terra úmida. 0 solo pulsava com batimentos ofegantes que reverberavam em cada grão de areia" (KANAFANI, G. Obras completas, vol. 1. Beirute, 1972, p. 37. Apud FARAH, 2011). 


\section{ensaio}

é submetido a um apartheid por irmãos e vizinhos, que por sua vez fugiam da tragédia do holocausto (WATZAL, 2007, ABU-RABI, 2011, p. 124). Acredito que o conhecimento que temos sobre o holocausto que os judeus sofreram sob os nazistas é uma página bem estabelecida e documentada da história do século XX, pelo que tenho procurado apresentar a perspectiva palestina do conflito, cuja narrativa ainda é pouco conhecida e pouco explorada no Brasil. Portanto, não é o caso de estender-me em explicações minuciosas sobre a perseguição nazista contra judeus na Europa do início do século XX.

Já sobre a expressão apartheid, ela foi usada mais recentemente por Mustafa Bartghouti, médico, militante e político palestino. A ocasião da utilização da palavra em seu artigo foi a reunião ocorrida entre o recém empossado presidente dos Estados Unidos, Donald Trump, e o primeiro ministro Benjamin Netanyahu. Bartghouti disse: "Os palestinos não estão dispostos a viver como escravos dos ocupantes em um sistema racista de apartheid" (trad. livre; "Palestinians are unwilling to live as slaves to the occupiers in an apartheid racist system.") (KUTTAB, 2017). A referência ao apartheid foi aplicada ao governo minoritário israelense sobre uma população palestina majoritária e será mais explorada adiante neste ensaio.

Aquestão da ocupação da terra provoca resistência de parte a parte. Israel se empenha em fortalecer o poder de repressão do seu exército, como foi demonstrado por Shlaim (2004, passim) em diversas ocasiões desde 1948. Shlaim deixa exaustivamente claro em sua obra que esse empenho tem certas nuanças religiosas (seja pela ideologia sionista que se torna como uma religião, seja pela insistência em uma Palestina "bíblica"; FLINT, 2009, p. 137). Do lado palestino, Abu Sway ${ }^{13}$ associa o tema da terra ao Movimento de Resistência Islâmica, o Hamas, e à religião, dizendo que o esforço do Hamas pela "questão da terra, conforme apresentada no decreto do Hamas, é consistente com a teologia e a jurisprudência islâmicas" (in ABU-RABI, 2011, p. 131). Ainda que o mencionado "decreto do Hamas" tenha sido abandonado (se não totalmente, em boa medida), é inegável o caráter islâmico do grupo palestino. ${ }^{14}$

Diante de ambos os quadros, portanto, há orientação dos esforços de ambos os povos a partir de pressupostos e objetivos religiosos.

\footnotetext{
${ }^{13}$ Abu Sway, desde 1996 é Professor de Filosofia e Estudos Islâmicos em Al-Quds University (Jerusalém).

${ }^{14}$ Em meu artigo de 2015 está demonstrado como o Hamas avançou em uma plataforma política em relação ao primeiro Estatuto do grupo, formulado na fundação do mesmo na década de 1980. Na ocasião da campanha política eleitoral em 2005 novas propostas foram apresentadas. V. A legitimidade internacional do Hamas (PAGANELLI, 2015).
} 


\section{O APARTHEID PALESTINO E A TRANSITORIEDADE DO VALOR DA VIDA HUMANA}

O Apartheid foi a política de governo na África do Sul a partir de 1949, um ano após a fundação do Estado de Israel. Inicialmente incluía a proibição de casamentos entre brancos e pessoas de outras etnias, relações sexuais entre negros e brancos. A Lei do Registro da População, daquele ano, que serviu de base para o apartheid, classificava os sul-africanos em Bantos (negros africanos), coloridos (mestiços) e brancos. A quarta categoria, asiáticos (indianos e paquistaneses), foi adicionado posteriormente (CASALS, 2010, p. 75-79).

Em alguns casos, a legislação dividiu famílias, uma vez que os pais poderiam ser classificados como brancos, enquanto os seus filhos foram classificados como coloridos. A Lei incluiu atos sobre a propriedade da terra (tenha em mente o que foi comentado há pouco sobre a relação do palestino com a terra), ficando $87 \%$ das delas com a minoria branca e $80 \%$ da população de origem negra com os 13\% restantes (CASALS, 2010, p. 7579). Se considerarmos inicialmente essas restrições impostas aos negros sul-africanos, podemos traçar de imediato uma analogia com a divisão de famílias e de comunidades palestinas inteiras na Cisjordânia quando, por exemplo, Israel iniciou a construção do Muro em 2002. ${ }^{15}$ Evidentemente que o Muro (que Israel chama Cerca), é medida recente, tomada para conter o avanço de terroristas palestinos, mas há décadas que a construção de assentamentos judaicos realiza efeito de apartheid semelhante (se não pior) há décadas contra a comunidade e as famílias na Cisjordânia, pressionando ou empurrando a ocupação do solo por palestinos para áreas cada vez menores e mais marginais de toda a terra, num resultado semelhante ao ocorrido na África do Sul.

Entre outras medidas restritivas adotadas no país africano após a implementação da referida Lei, estavam: limitar o contato entre as raças, instalações públicas separadas para brancos e não-brancos, limitação da atividade dos sindicatos de trabalhadores não-brancos e negação da participação de não-brancos no governo nacional. De 1961 a 1994, mais de 3,5 milhões de pessoas foram retiradas à força de suas casas e depositadas em bantustões (sistema de segregação habitacional), onde foram mergulhados na pobreza e na falta de perspectivas, ${ }^{16}$ o que facilmente encontra paralelo com a situação dos assentamentos para refugiados, à exemplo do que ocorreu quando palestinos ficaram confinados em Gaza (o bantustão palestino) e foram, posteriormente, isolados do restante dos palestinos da Cisjordânia. Segundo o comitê para refugiados das Nações Unidas (UNRWA), há hoje cerca

${ }^{15}$ V. e.g., MIDDLE East Monitor. Separation wall divides palestinian families. MEMO-Middle East Monitor, Disponível em <https://www.middleeastmonitor.com/20140504-separation-wall-divides-palestinian-families/> e acessado em 06.08.2017; KESTLER-D’AMOURS, Jillian. Israeli wall isolates palestinian communities. Al Jazeera English, Disponível em <http://www.aljazeera.com/indepth/features/2012/12/20121225825178322.html> e acessado em 06.08.2017.

${ }^{16}$ Disponível em A\&E Network Digital, <http://www.history.com/topics/apartheid> acessado em 02.10.2016. 
de 5 milhões de palestinos vivendo como refugiados e proibidos de retornar para suas antigas casas, ${ }^{17}$ situação mais ampla do que a ocorrida no apartheid sul africano.

Até o período dos mandatos britânico e francês, os povos no Oriente Médio não dividiam suas terras como as nações modernas faziam, com fronteiras protegidas e demarcadas artificialmente. Os territórios de cada tribo eram conhecidos entre si. Membros de uma tribo ou etnia transitariam livremente nos termos vizinhos quando eram celebrados pactos amistosos entre os líderes tribais, o que permitia alguma liberdade de trânsito, como também privilégios quando estabelecidos nos pactos entre tribos. Assim como os banto, coloridos, brancos e asiáticos na África do Sul, as diferentes famílias árabes-palestinas regulavam as relações internas da comunidade que ocupava a terra havia séculos.

O conceito moderno de nação, como entendemos no Ocidente, é relativamente novo, não tem mais do que duzentos anos. Foi a expansão mercantil (também tratada como colonialismo), por parte de países europeus, como a Portugal, França, Holanda, Inglaterra e outros, que criou as condições para que posteriormente países como a Indonésia e a Índia, antes divididos simplesmente por tribos e/ou etnias, fossem formalmente criados. O mesmo pode ser dito da Arábia Saudita, da Jordânia, do Iraque, do Irã, e a própria Palestina, como já vimos anteriormente, cujo povo ainda hoje não teve a sua situação ou status territorial resolvido por meio do reconhecimento dos países membros da ONU. Hoje a Palestina é governada pela Autoridade Palestina, organismo que representa os interesses do povo palestino na comunidade internacional. Na ONU, a Palestina participa como "Estado observador não-membro", status reconhecido em 29 de novembro de 2012. ${ }^{18}$

Embutida nas disputas por terras e novos mercados para exploração mercantil estão questões políticas e econômicas, as quais não devem implicar ou interferir na diminuição do valor da vida humana, que é inalienável, evidentemente; o valor das vidas de árabes e palestinos (chamados de indígenas ou população autóctone nos estudos antropológicos) e judeus não devem ser categorizados como superior ou inferior por conta das disputas nos campos político ou econômico. As personalidades que se destacaram no cenário internacional por seus pensamentos, atitudes, exemplos e esforços na procura pela paz entre povos em atrito ou conflito souberam valorizar adequadamente essa questão central e inalienável, a vida humana, quando foram projetadas para as diferentes nações ao redor do globo, e passaram a ser admiradas por cada um de nós. Refiro-me a Gandhi, Mandela, Malala, Tutu, Gülen e tantos outros.

\footnotetext{
${ }^{17}$ Palestine Refugees, UNRWA. Disponível em <https://www.unrwa.org/palestine-refugees> e acessado em 06.03 .2017

${ }^{18}$ V. http://www.bbc.com/portuguese/noticias/2012/11/121127_palestinos_onu_pai.shtml acessado em 20.02.2017. Veja mais em PAGANELLI, A legitimidade internacional do Hamas. Disponível em https:// www.academia.edu/15979814/A_LEGITIMIDADE_INTERNACIONAL _DO_HAMAS, paper produzido em 2015 no âmbito das pesquisas de doutoramento em História Social (FFLCH/USP).
} 
Todo o esforço feito no campo intelectual não fará sentido se não visar a melhoria da vida na sociedade, sendo essa melhoria percebida primeiramente por nós mesmos. Eu melhoro a mim e assim posso tentar a melhoria da vida do outro. Em muitos casos, os personagens acima pensaram no outro e por vezes esqueceram-se de si. Malala é um exemplo de que a própria vida, que sofrera um forte atentado, pode ser colocada em risco pela educação das meninas paquistanesas, um risco que ela considerou válido.

A população palestina é pouco superior a 4,9 milhões $^{19}$ (Cisjordânia, Faixa de Gaza e Jerusalém Oriental), além dos mais de 5 milhões que vivem em campos de refugiados no Líbano, na Jordânia, no Iraque e na Síria. Se somarmos os árabes palestinos cidadãos de Israel, o número de palestinos chega a 5,2 milhões (fora os refugiados, cerca de 5 milhões ${ }^{20}$ ). 0 senso comum por vezes é rápido ao chamar os palestinos de invasores, especialmente em setores da Igreja evangélica brasileira com forte influência da teologia dos Estados Unidos - já ouvi cristãos dizer que os palestinos são, inclusive, "perigosos". Naim Ateek, palestino e bispo anglicano (cristão) em Jerusalém disse:

[...] esses jovens não nasceram "terroristas". Ninguém nasce um terrorista. Eles nasceram imagem e semelhança de Deus. Eles nasceram os seres humanos com amor a vida e a liberdade. Todos eles, sem exceção, nasceram sob a ocupação militar israelense. (ATEEK, 2002) ${ }^{21}$

Os palestinos são vidas humanas com valor inestimável, e vida é o assunto predileto $\mathrm{d}$ as religiões, a de Jesus, a dos judeus e a dos muçulmanos. 0 bispo emérito da África do Sul, o anglicano Desmond Tutu, vencedor do Prêmio Nobel da Paz em 1984, declarou: "Sou cristão, e muitos palestinos são cristãos - para ser mais exato, a maioria é anglicana" (TUTU, 2012, p. 106). Embora os partidos políticos palestinos não sejam de orientação cristã, houve respeito aos cristãos de Belém e a seus símbolos por parte dos líderes islâmicos. Nas eleições palestinas de 2006, cristãos votaram no Hamas, que venceu as eleições derrotando o Fatah, partido de orientação nacionalista (KARMI, 2006, p. 8). Uma vez eleito, o Hamas nomeou um cristão para seu ministro do turismo (HROUB, 2009, p. 22). Isso fala muito sobre o Hamas, mas fala mais sobre a alma palestina, a prioridade dada à terra e àqueles que nela formaram suas vidas, famílias e comunidade. ${ }^{22}$

${ }^{19}$ Com dados de $<$ http://www.worldometers.info/world-population/state-of-palestine-population/> acessado em 20.02.2017.

${ }^{20}$ Disponível em <https://www.unrwa.org/palestine-refugees> e acessado em 20.02.2017.

${ }^{21}$ Com relação ao tratamento e apoio irrestrito dado aos judeus (como também à sua política de Estado) pela Igreja brasileira, Russell Shedd (1929-2016), teólogo colombiano filho de missionários norte-americanos, um dos principais pensadores e escritores protestantes a ter trabalhado no Brasil, comentou que tem sido frequente pensar nos judeus como "irmãos" de Jesus (baseado em Mateus 25.40) e que "nações como o Brasil ou os Estados Unidos devem tratar bem os israelitas, porque as nações que assim atuarem serão galardoadas [por Deus] por todo benefício que estenderam a Israel [...] Mas tal interpretação não cabe a esta passagem. Jesus mesmo declarou que seus 'irmãos' eram os que nele criam" (SHEDD, 1995, p. 27).

${ }^{22}$ Em relação ao Hamas, ele tem sido acusado de não se envolver na pauta jihadista internacional, e com razão, porque sua agenda é a luta pela Palestina, prioritariamente. 
A ocupação dos territórios palestinos pelo exército e colonos israelenses tem sido um drama para a vida de milhares de famílias. Guila Flint, jornalista israelense que trabalhou em Tell Aviv, escreveu que no início da década de 2000 (quando havia colônias de assentamentos israelenses que estrangulavam a vida palestina na região), somente na Faixa de Gaza viviam 1 milhão de palestinos e 5 mil colonos israelenses que controlavam $30 \%$ das terras e $40 \%$ das fontes de água: é desproporcional, tal qual o apartheid. "Grande parte das reservas subterrâneas de água é canalizada para os assentamentos e para o território de Israel" (FLINT, 2009, p. 56).

A liderança dos colonos está nas mãos do setor ideológico. Movidos por uma visão nacionalista-religiosa, os colonos militantes acreditam que a chamada Terra de Israel bíblica pertence exclusivamente ao povo judeu e que os palestinos são intrusos nesses territórios. (FLINT, 2009, p. 137)

Flint reportou os "generosos subsídios do governo para a moradia nos territórios ocupados" e que "aos colonos foram oferecidos empréstimos muitos favoráveis e isenção de impostos". Como se isso não bastasse, "os assentamentos cercam as áreas palestinas, impedindo qualquer crescimento das cidades e aldeias palestinas" (FLINT, 2009, p. 138). No filme-documentário Cinco Câmeras Quebradas, ${ }^{23}$ há depoimentos contra a interferência israelense nas propriedades palestinas dividindo-as ao meio pela construção do Muro, a partir de 29 de março de 2002, separando famílias palestinas e também separando o espaço da moradia do terreno cultivado há décadas para sustento da família. 0 documentário também relaciona a ação de colonos que atearam fogo a oliveiras, que é base que sustenta a agricultura e parte essencial da economia palestina. Os prejuízos econômicos são imensos.

$\mathrm{Na}$ mais devastadora onda de ataques dos últimos anos, conhecida como "a Guerra dos 50 dias", em meados de 2014, a United Nations Office for the Coordination of Humanitarian Affairs (OCHA) estimou em 1486 civis palestinos mortos, dos quais mais de 500 eram crianças e 11.000 foram os feridos. Mais de meio milhão de pessoas foram deslocadas e 108.000 ficaram desalojadas (OCHA, 2014, p. 1). Para ficarmos apenas neste conflito de 2014, outro relatório da ONU tratou da destruição da infraestrutura em Gaza: 18.000 unidades habitacionais destruídas total ou parcialmente, as redes de eletricidade e a infraestrutura de água e saneamento foram incapacitadas e 73 instalações médicas e diversas ambulâncias foram danificadas. E o texto acrescenta que o "impacto severo nos direitos humanos dos palestinos em Gaza [...] serão sentidos para as gerações vindouras" (ONU, 2015, p. 7), com apontamento para violações nos mesmos direitos humanos dos moradores da Cisjordânia e Jerusalém Oriental.

\footnotetext{
${ }^{23}$ Les Cinqs Câmeras Brisées, França, 2011, foi filmado por Emad Bornat, morador de Bil’In, uma vila na Cisjordânia. 0 documentário mostra os protestos dos palestinos contra a construção de assentamentos israelenses em sua terra, e especialmente sua luta contra a construção do Muro (ao qual Israel chama de cerca), que separa seus territórios dos territórios israelenses.
} 
Quando lemos que instalações médicas foram danificadas, precisamos nos lembrar que pesquisas e coletas de dados sobre toda a população atendida foi comprometida ou totalmente perdida: relatórios, exames médicos, fichas de doentes. ${ }^{24} \mathrm{~A}$ devastação, porém, não é ocasionada somente pela construção do muro a partir de 2002 ou pela Guerra dos 50 dias, em 2014; ela ocorre há décadas com alguns períodos de agravamento. Por exemplo:

[...] após a ocupação israelense da Cisjordânia e de Gaza em 1967, a mesma política de destruição foi implantada nessas áreas; no fim de 1969, 7.554 residências árabes foram arrasadas e, em 16 de agosto de 1971, 212 casas foram demolidas, segundo o londrino Sunday Times de 19 de junho de 1977. (SAID, 2012, p. 17)

Os efeitos são sentidos na atividade mineradora, que também sofre prejuízos, na distribuição de recursos hídricos, na mobilidade e nas possibilidades de trabalho. É um sufocamento sistemático e amplo que aqui tomamos como referência para compreender e comparar ao apartheid africano, como é a nossa proposta.

\section{A ÁFRICA DO SUL E 0 "PARADIGMA DE MANDELA”}

Nações e grupos organizados por vezes se servem do recurso ao terror a fim de "legitimar a violência" (HANIF, 2014). Mandela, hoje considerado um ícone na luta pelos direitos, ontem fez terror contra o Estado. "Nelson Mandela, agora um herói, foi preso porque se recusou a pedir a seus seguidores que se abstivessem de violência" (HANIF, 2014). Com o fim das atividades do Congresso Nacional Africano (CNA) em 1960 (v. nota 16), movimento e partido do qual era vice-presidente, ele passou à clandestinidade e introduziu "uma campanha de sabotagem contra a economia do país" para derrubar o governo (HANIF, 2014), o que ele mesmo admitiu diante do tribunal:

Eu não nego que planejei sabotagem. Não planejei isso com espírito imprudente,
nem porque tivesse amor à violência. Isso se deu como resultado sereno e sóbrio
da avaliação de um ambiente da situação política que surgiu depois de muitos
anos de tirania, exploração e opressão do meu povo pelos brancos. (HANIF, 2014)

Nelson Rolihlahla Mandela, ou simplesmente Mandela, nasceu em Mvezo em 18 de julho de 1918. Estudou Direito na "Universidad de Fort Hare em Cabo del Este, uma instituição de elite que formava alunos negros ao estilo ocidental" (CASALS, 2010, p. 7579). De Fort Hare ele foi expulso por causa da sua militância, mas recebeu o título de advogado em sua passagem pela Universidade de Witwatersrand, em Johannesburgo. Foi lá que conheceu Walter Sisulu e Oliver Tambo, ${ }^{25}$ militantes anti raciais com quem Mandela

\footnotetext{
${ }^{24}$ FLINT (2009, p. 183) fez observação semelhante e mais detidamente.

${ }^{25}$ Foi sócio num escritório de advocacia, Mandela \& Tambo (1952-1958), onde defendeu centenas de causas de negros contra o regime do Apartheid (MANDELA, 2010, p. 384-387).
} 


\section{ensaio}

formou a ala juvenil do CNA, e o ativista comunista branco, Joe Slovo, que moldaria sua posição política (CASALS, 2010, p. 75-79). Com Mandela, o CNA “passou de 7 mil para 100 mil membros em resposta ao endurecimento das leis raciais e o surgimento das políticas do Apartheid" (CASALS, 2010, p. 75-79).

Mandela foi preso várias vezes, por adesão ideológica, por sair do país sem passaporte, pela mobilização contra as leis de segregação. Em 1961, o CNA criou um braço armado, o Umkhonto we Sizwe (Lança de uma Nação, trad. livre), identificado pela sigla MK, que teve Mandela como primeiro comandante. A atuação militar do MK respondia aos massacres promovidos pelo Governo, que à época entendia que a não-violência não era uma opção adequada. Mandela estudou vários movimentos civis, militares e de resistência ${ }^{26}$ ao redor do planeta, viajou e deu palestras, trabalhou para ganhar apoio à causa dos negros em seu país, mas um fato que o deixou impressionado ele o encontrou em sua própria terra natal, entre a minoria hindu em Durban, a terceira maior cidade do país. Trata-se das ideias pacifistas de Mahatma Gandhi (CASALS, 2010, p. 75-79).

Gandhi chegou a comparar a situação dos judeus em relação aos cristãos com a situação dos intocáveis na Índia em relação às demais castas (BUBER, 2005, p. 107), e a despeito de seus argumentos, muitos judeus (Martin Buber incluído) rejeitaram suas ideias. Na carta, Gandhi apelou para a ligação com a terra, aprofundando a questão quanto ao nascimento nela: "The jews born in France are French" (Os judeus nascidos na França são franceses, trad. livre; BUBER, 2005, p. 108). Lar é onde nascemos e crescemos. Gandhi também apelou à fé judaica, dizendo que Jehovah, o Deus dos judeus, é mais pessoal do que as divindades dos cristãos, dos muçulmanos ou dos hindus, e sendo ele essencialmente Um sem aliados, exerce governo central (pelo que seria mais fácil aglutinar os judeus à sua volta), cuja influência deveria ser melhor aproveitada no esforço conjunto de resistência não-violenta (BUBER, 2005, p. 109). Os judeus não deveriam sentir-se impotentes cultuando uma divindade assim.

Buber (1983) respondeu por carta a Gandhi, uma peça realmente exemplar do ponto de vista prático e considerando a lógica dos fatos. Ele diz ter lido e relido as sentenças no artigo de Gandhi sem ser capaz de entender ( $I$ read and reread these sentences in your article without bring able to understand; (BUBER, 1983, p. 114), mesmo usando boa vontade. 0 filósofo procura demonstrar os danos sofridos ao patrimônio (sinagogas, rolos da Lei, lojas etc.), o que não encontra paralelo na cultura/religião hindu; depois indica que Gandhi e seu povo não passaram pelas crueldades dos campos de concentração e os métodos de rápido extermínio, e que Gandhi não cogitasse dizer que os sofrimentos de ambos os povos foram", já que judeus na Alemanha não podiam falar na rua sem correr o risco de serem apedrejados, coisa que os indianos na África do Sul sequer passaram próximos de experimentar (BUBER, 1983, p. 116).

${ }^{26}$ Sobre o conflito Israel-Palestina, leu The Revolt, de Menachem Begin [Dell Publishing Company, 2012]. CASALS, 2010, p. 75-79. 


\section{ensaio}

Buber segue reunindo argumentos e apresentando pontos na tentativa de demonstrar que não se podia comparar a situação de ambos os conflitos e que, portanto, o reducionismo de Gandhi era absurdo quando ele dizia que tudo se reunia a um dilema existencial condensado na seguinte fórmula: “A Palestina pertence aos árabes” (BUBER, 1983, p. 120). Não será necessário aprofundar as breves reflexões de Buber, todas muito objetivas, concordo, mas penso que o ponto aqui é a comparação possível de ser observada hoje, o resultado que cada conflito (e cada medida adotada) produziu ao longo do tempo. Tanto na África do Sul (entre os hindus, brancos e negros) quanto na própria Índia, a despeito das injustiças econômicas, a situação de conflito, tal como antes se notava, não existe. Isso é fato.

Gandhi propôs observar a campanha Satyagraha entre os hindus sul-africanos como um "exato paralelo". Satyagraha era a prática que envolvia "a força da verdade e do amor, que defendia a resistência não fazendo sofrer o oponente, mas a si mesmo, para humilhálo e sensibilizar-lhe o coração". ${ }^{27}$ A esse modelo de resistência sem violência, que privilegia a busca pela verdade mobilizando a população, Mandela juntou a sua formação ocidental a fim de definir seus métodos de luta pacífica e inclusão das minorias mestiças, asiáticas e demais no esforço contra o Apartheid (CASALS, 2010, p. 75-79).

O movimento armado e seus simpatizantes sentiram-se traídos pelo novo discurso de Mandela, pelo que o delataram. No que ficou conhecido como "julgamentos Rivonia", Mandela foi o acusado número 1. Ele mesmo fez sua defesa por quatro horas no texto chamado "A luta é a minha vida", assumindo a responsabilidade (ele fora preso juntamente com seu amigo Sisulu), e anunciando as bases de sua ideologia:

\footnotetext{
Lutei contra a dominação branca e contra a dominação negra. Tenho procurado o ideal de uma sociedade democrática e livre em que as pessoas vivam em harmonia e tenham oportunidades iguais. Este é um ideal que espero viver e espero alcançar. Mas, se necessário, também é o ideal pelo qual estou disposto a morrer. (CASALS, 2010, p. 75-79; trad. livre) ${ }^{28}$
}

Mandela, que aos 46 anos já havia sido condenado em duas ocasiões a períodos menores de reclusão, foi condenado à prisão perpétua a ser cumprida em Robben Island, na Cidade do Cabo, sob inscrição número 46664. Mas ele tinha força de mobilização social e experiência política necessárias para comandar a luta contra o Apartheid. Seria desonesto considerar somente aspectos públicos de sua formação e da construção de sua identidade pessoal na elaboração dos eixos sobre do seu modelo de resistência. A Satyagraha de Gandhi já exercera influência sobre ele e não podemos diminuir a provável cultura tribal de sua infância e adolescência. Mas outro nome se destaca por ter lutado a mesma luta de

\footnotetext{
${ }^{27}$ Melanie Retz (ed.) Gandhi, Grandes líderes religiosos. Ano 1, nº 1, 2014. Bauru: Alto Astral Ed., p. 9.

28 "He peleado contra el dominio blanco y he peleado contra el dominio negro. He favorecido el ideal de una sociedad democrática y libre en la cual las personas vivan en armonía y con iguales oportunidades. Es un ideal por el que espero vivir y que espero lograr. Pero, si es necesario, es un ideal por el cual estoy preparado a morir".
} 
Mandela, por onde é devido afirmar ter havido um paradigma espiritualista envolvido na formação das diretrizes que regeram a atuação de Mandela.

O bispo sul-africano Desmont Tutu (2012), seu amigo pessoal, traz bons insights sobre processos de reconciliação e pacificação de comunidades em conflito, haja vista o seu envolvimento durante e após o Aparthaid na África do Sul. Tutu conheceu o conflito na Palestina, onde esteve em 1989. Ele fez um discurso no Natal daquele ano, na igreja Old South, em Boston, intitulado "Ocupação é opressão". Um dos anfitriões do encontro era Naim Ateek, fundador do Centro Ecumênico de Teologia da Libertação Palestina "Sabeel" de Jerusalém. No discurso, Tutu (2012, p. 118-126) fez associações da ocupação israelense com o Apartheid sul-africano. Algumas de suas afirmações são:

\footnotetext{
Não há meio pelo qual a força se transforme em justiça [...]; Eu testemunhei a humilhação dos palestinos nos bloqueios rodoviários [...] a exigência áspera e descortês por identificação dos palestinos foi uma lembrança sinistra das infames reides da lei do passe do horrendo regime do apartheid [...] Nessas visitas, nós vimos ou lemos a respeito de situações que não aconteceram nem durante o apartheid na África do Sul: a demolição de casas com base na suspeita de que um membro da família fosse um terrorista, de modo que todos pagavam o preço nesses atos de punição coletiva que, aparentemente, se repetem nos recentes ataques aos campos de refugiados árabes. Não sabemos a verdade exata porque os israelenses não permitem a presença da imprensa; Nós condenamos a violência dos homens-bomba e, se as crianças árabes são ensinadas a odiarem judeus, também condenamos a corrupção das mentes jovens (TUTU, 2012, p. 120-123, ênfase acrescentada e no original).
}

Mandela propôs desenvolver uma consciência da situação crítica em que as diferentes etnias estavam envolvidas, estimulando "pontes de entendimento entre os diferentes grupos", sem considerar como ferramenta qualquer proposta de reação violenta ou intolerante, virtude rara nos líderes em todo o século XX. Com isso, atraiu a atenção internacional para a sua luta, além do embargo econômico por parte dos Estados Unidos e nações na Europa. Com o isolamento, partiu do Regime a iniciativa, no começo oculta, de procurar Mandela para negociar uma saída política para o Apartheid. A partir de $1 \underline{0}$ fevereiro de 1990 tiveram início as medidas oficiais para a abolição do Apartheid, a tirada dos partidos da clandestinidade e a liberação de presos políticos, incluindo Mandela, solto no dia 11 daquele mês (CASALS, 2010, p. 75-79).

Mandela se tornou o primeiro presidente negro da África do Sul, cargo que ocupou de 1994 a 1999. Ele faleceu em Johanesburgo em 2013. Mandela conseguiu aglutinar em torno de seus ideais diferentes grupos étnicos em seu país, pelo que vemos expresso nas palavras de Desmont Tutu o que ocorreu ali: "Não é possível haver futuro sem perdão. Jamais haverá um futuro sem que haja paz. Jamais haverá paz sem que haja reconciliação. Mas não haverá reconciliação antes de existir perdão. E jamais existirá perdão sem que as pessoas se arrependam" (TUTU, 2012, p. 54). 


\section{CONSIDERAÇÕES FINAIS}

É considerável o apelo da espiritualidade na vida de Mandela e na solução para o problema do Apartheid e da segregação racial nem seu país. Mas não podemos nos desviar da seguinte indagação: Como se espera que judeus e palestinos olhem com seriedade para propostas espiritualistas, quando precisam resolver conflitos de natureza política e social? Satyagraha, discurso sobre perdão e reconciliação parecem fantasias irrealizáveis quando olhamos para a Palestina e para Israel. Não ignoramos a formação política dos personagens. Mandela militou no comunismo sul-africano. A formação em Direito que Gandhi recebeu na Londres do final do século XIX certamente o expôs a uma escola ideológica próxima a de Mandela. No entanto, ambos aplicaram a espiritualidade na elaboração de seus métodos e, embora haja bolsões de pobreza na Índia e na África do Sul a situação econômica da população não seja diferente (Mandela foi acusado de não promover desenvolvimento enquanto foi presidente), ambas as nações foram pacificadas e os diversos e diferentes grupos étnicos que os compõem hoje vivem em relativa paz.

A ideia de olhar com atenção ao aspecto da espiritualidade não é particularmente original, mas tampouco absurda. 0 prestigiado Programa de Negociações na Harvard Law School, liderada pelo dr. William Ury, criou o Abrahams Path, ${ }^{29}$ que parte de uma narrativa religiosa comum entre os três grupos monoteístas (israelenses e palestinos inclusos) para promover o diálogo, o desenvolvimento conjunto e alcançar a paz. Ninguém se torna um herói sozinho e seguramente ninguém alcançará a paz sozinho. É na cooperação que cada povo e cada indivíduo chegará à paz desejada, duradoura e justa e nesse esforço global, nenhuma alternativa pode ser descartada, ainda que aparentemente inadequada ou presumivelmente ineficiente.

Que em nossos dias os jovens proponham a paz e lutem por ela, por quaisquer meios, e sejam bem-sucedidos em seus esforços, mais do que fomos até aqui.

\footnotetext{
${ }^{29}$ Saiba mais sobre Abrahams Path em <http://www.pon.harvard.edu/category/research_projects/ meni/ abrahamspath/> disponível e acessado em 03.10.2016.
} 


\section{REFERÊNCIAS}

ABU-RABI', Ibrahim M. (org). O guia árabe contemporâneo sobre o islã político, trad. André Oídes. São Paulo: Madras, 2011.

ASSOCIETED Press in Jerusalem. Israeli court rules against illegal settlement. 26.mar.2012.

ASTON, John. Israel boycott ban: Local councils face legal action at High Court over boycott on Israeli goods made in West Bank. 4.mai2016. Disponível em <http://www. independent.co.uk/news/uk/home-news/israel-boycott-ban-local-councils-face-legalaction-at-high-court-over-boycott-on-israeli-goods-made-a7012351.html > e acessado em 01.10 .2016

ATEEK, Naim. Suicide bombers: What is theologically and morally wrong with suicide bombing? A Palestinian Christian Perspective, in Studies in World Christianity, vol. 8, $\mathrm{n}^{0} 1$, 2002.

A\&E Network Digital, disponível em <http://www.history.com/topics/apartheid> acessado em 02.10.2016.

BEGIN, Menachem. The Revolt. New York: Dell Publishing Company, 2012.

BOURDIEU, Pierre. A economia das trocas simbólicas, 7ạ ed. São Paulo: Perspectiva, 2011.

BUBER, Martin. A Land of Two Peoples, Martin Buber on Jews and Arabs. Chicago: The University of Chicago Press, 1983.

BURNET, Emad; DAVIDI, Guy. Les Cinqs Câmeras Brisées, França, 2011. Documentário franco-palestino-israelense dirigido por Emad Burnat e Guy Davidi.

CASALS, Xavier. Mandela: El forjador de una nueva Sudáfrica. In Clío - Revista de História, $\mathrm{n}^{\circ}$ 100. Barcelona: MC Ediciones, 2010, p. 75-79.

FARAH, Paulo. D. A relação com a terra na obra do escritor palestino Ghassan Kanafani. Dossiê Estudos Árabes \& Islâmicos. Revista Litteris, nº 7, mar. 2011.

FARHAT, José. Falácias em torno de Israel e do sionismo - parte 3. São Paulo: Icarabe, 2013. Disponível em <http://www.icarabe.org/articulistas/jose-farhat> e acessado em $1^{\circ} .10 .2016$.

FLINT, Guila. Miragem de paz - Israel e palestina, processos e retrocessos. Rio de Janeiro: Civilização Brasileira, 2009.

GUNNEWEG, Antonius H. J. História de Israel, dos primórdios até Bar Kochba e de Theodor Herzl até os nossos dias. São Paulo: Teológica/Loyola, 2005.

HANIF, S. The difference between freedom-fighters and terrorists is not perception but terminology, in Media Monitors Network, California, 2003. Disponível em <http://www. mediamonitors.net/sabiahanif1.html>, acessado em 15.04.2014. 
HROUB, K. Hamas, um guia para iniciantes, 2ª ed. Rio de Janeiro: Difel, 2009.

KAMEL, Ali. Sobre o Islã - a afinidade entre muçulmanos, judeus e cristãos e as origens do terrorismo. Rio de Janeiro: Nova Fronteira, 2007.

KARMI, Omar. Understanding Hamas' Victory in Jerusalem. In Jerusalem Quarterly, issue 26. Institute for Palestine Studies, 2006.

KESTLER-D’AMOURS, Jillian. Israeli wall isolates palestinian communities. Al Jazeera English, Disponível em <http://www.aljazeera.com/indepth/ features/2012/12/20121225825178322.html> e acessado em 06.08.2017.

KNOWLTON, S. Sírios e Libaneses: Mobilidade social e espacial. São Paulo: Anhamb, 1961.

KUTTAB, Daoud. Why Arab leaders cannot replace legitimate Palestinian ones. Palestine Pulse in Al-Monitor, 16.02.2017, disponível em http://www.al-monitor.com/pulse/ originals/2017/02/trump-two-state-solution-arab-leaders-palestinian-conflict.html?utm_source=Boomtrain\&utm_medium =manual\&utm_campaign $=20170217 \& b t$ ee=upZuGef+Cr3msNoPqFw7VyyKQimYbLl1oxug0+vQZrrMUL7hXltlBEZWDmdCe4ZL\&bt_ts=1487356120772\# e acessado na data da publicação.

MANDELA, Nelson. Conversas que tive comigo. Rio de Janeiro: Rocco, 2010. p. 30-33.

MIDDLE East Monitor. Separation wall divides palestinian families. MEMO-Middle East Monitor, Disponível em <https://www.middleeastmonitor.com/20140504-separationwall-divides-palestinian-families/> e acessado em 06.08.2017

OCHA, United Nations Office for the Coordination of Humanitarian Affairs. Humanitarian Bulletin. Monthly Report, june-august 2014.

ONU. Report of the independent commission of inquiry established pursuant to Human Rights Council resolution S-21/1. In Human Rights Council, Twenty-ninth session, Agenda item 7. Human rights situation in Palestine and other occupied Arab territories, 24 June 2015.

PAGANELLI, Magno. A relação entre a violência do Hamas e a interpretação do Corão. Dissertação [Ciências da Religião]. São Paulo: Universidade Presbiteriana Mackenzie, 2014a.

PAGANELLI, Magno. A legitimidade internacional do Hamas. Disponível em <https:// www.academia.edu/15979814/A_LEGITIMIDADE_INTERNACIONAL_DO_HAMAS>. Paper produzido em 2015 no âmbito das pesquisas de doutoramento em História Social (FFLCH/USP).

PAGANELLI, Magno. Milênio: o tempo que o homem busca, o mundo que Deus pode dar, $2^{\text {a }}$ ed. São Paulo: Arte Editorial, 2014b.

PÉREZ, Joseph. History of e Tragedy: The expulsion of the Jews from Spain. Urbana and Chicago: University of Illinois Press, 2007. 


\section{ensaio}

RETZ, Melanie (ed.). Gandhi, Grandes líderes religiosos. Ano 1, no 1, 2014. Bauru: Alto Astral Ed.

SAID, Edward W. A questão da Palestina. São Paulo: Ed. Unesp, 2012.

SHEDD, Russell P. A escatologia do Novo Testamento, 2ª ed. São Paulo: Vida Nova, 1995.

SHLAIM, Avi. A muralha de ferro, Israel e o mundo árabe. Rio de Janeiro: Ed. Fissus, 2004.

SOREL, George. Reflexões sobre a violência. São Paulo: Martins Fontes, 1992.

TRUZZI, O. M. S. Patrícios: Sírios e libaneses em São Paulo. São Paulo: Hucitec, 1997.

TUTU, Desmont. Deus não é cristão e outras provocações. Rio de Janeiro: Thomas Nelson, 2012.

UNRWA. Palestine Refugees. Disponível em <https://www.unrwa.org/palestinerefugees> e acessado em 06.03.2017

WATZAL, L. UN Report on Palestine: Military Occupations, Apartheid, and Torture. In PalestineChronicle.com de 23.04.2014. Acessado em 30.04.2014.

Texto recebido em: 30 de Outubro de 2016 Aprovado em: 24 de Março de 2017. 